\title{
Vibration Control of a Semiactive Vehicle Suspension System Based on Extended State Observer Techniques
}

\author{
Ze Zhang, ${ }^{1}$ Hamid Reza Karimi, ${ }^{2}$ Hai Huang, ${ }^{1}$ and Kjell G. Robbersmyr ${ }^{2}$ \\ ${ }^{1}$ School of Astronautics, Beihang University, Beijing 100191, China \\ ${ }^{2}$ Department of Engineering, Faculty of Engineering and Science, University of Agder, 4898 Grimstad, Norway \\ Correspondence should be addressed to Hamid Reza Karimi; hamid.r.karimi@uia.no
}

Received 3 March 2014; Accepted 2 May 2014; Published 20 May 2014

Academic Editor: Weichao Sun

Copyright (c) 2014 Ze Zhang et al. This is an open access article distributed under the Creative Commons Attribution License, which permits unrestricted use, distribution, and reproduction in any medium, provided the original work is properly cited.

\begin{abstract}
A feedback control method based on an extended state observer (ESO) method is implemented to vibration reduction in a typical semiactive suspension (SAS) system using a magnetorheological (MR) damper as actuator. By considering the dynamic equations of the SAS system and the MR damper model, an active disturbance rejection control (ADRC) is designed based on the ESO. Numerical simulation and real-time experiments are carried out with similar vibration disturbances. Both the simulation and experimental results illustrate the effectiveness of the proposed controller in vibration suppression for a SAS system.
\end{abstract}

\section{Introduction}

Vibration is a common and unpredicted phenomenon for dynamic and static bodies. Vibrations are detrimental to comfort in many places, and most of the applications in civil, mechanical, and electrical engineering are easily affected by undesirable vibration or even the complete system will lose functionality. Those vibrations are harmful and must be eliminated or reduced. Vibration reduction can be achieved in many different ways. From the difference of isolation components, vibration suppression systems can be divided into three categories: passive, semiactive, and active.

In the automobile industry, the vibration suppression system is introduced for decades. In a wheeled vehicle the mechanical system of springs and shock absorbers connect the wheels and axles to the chassis form vibration suspension system. The suspension system can provide stiffening and damping when the vehicle is running on an irregular road surface to isolate the vehicle body and ensure the comfort of the passengers. Many efforts were made to make the suspension system work in an optimal condition by optimizing the parameters of the suspension system passively; however, they have limitation of frequency range. Active suspensions were also introduced in [1-7], but the system is complex and in the need of much more power supply because of the added actuators. Semiactive concept combines the advantages of both active and passive suspensions and results in good performance with less complexity and power acquirement [8].

One of the semiactive suspension systems currently used for vibration isolation is equipped with magnetorheological (MR) damper which creates braking torque by changing the viscosity of the MR fluid inside the brake [9]. MR fluid has magnetically sensitive rheological properties. Varying the magnetic field strength by changing the input current has the effect of changing the viscosity of the MR field and this leads to the changing of the damper torque output [10]. Thus, the output torque of the MR damper can be controlled by changing the input current. For a MR damper and spring suspension system, the input current must be controlled properly in order to suppress vibration. Usually a feedback control with the information of the body position is introduced, such as PID control [11], neural network control [12], backstepping control [13, 14], fuzzy logic control [15], LQG [16], and Ho control [17].

In this paper, a practical feedback control solution for controlling the MR damper based on extended state observer (ESO), a part of active disturbance rejection control (ADRC) technology $[18,19]$, is applied. The ADRC has been successfully employed in many mechanical and electronic 


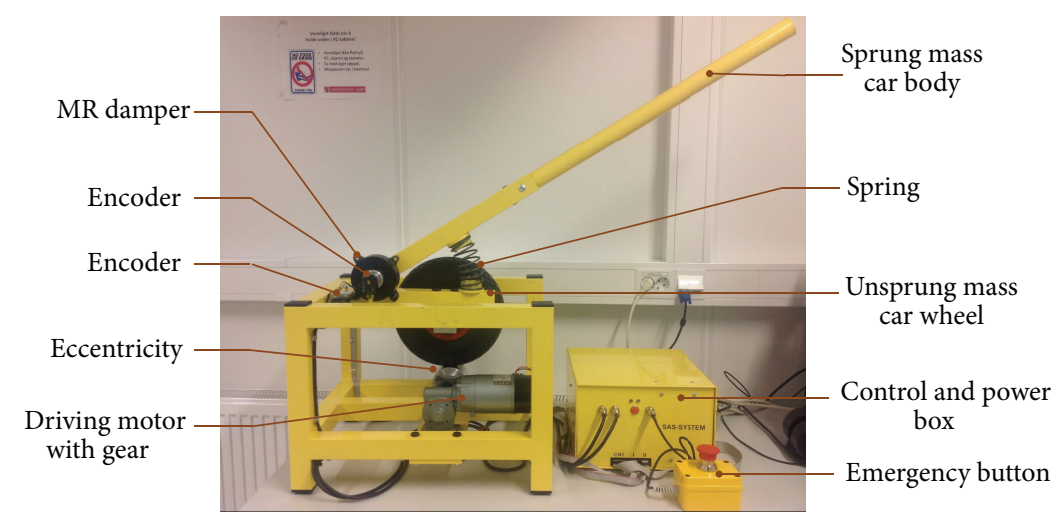

FIgURE 1: Semiactive suspension (SAS) system.

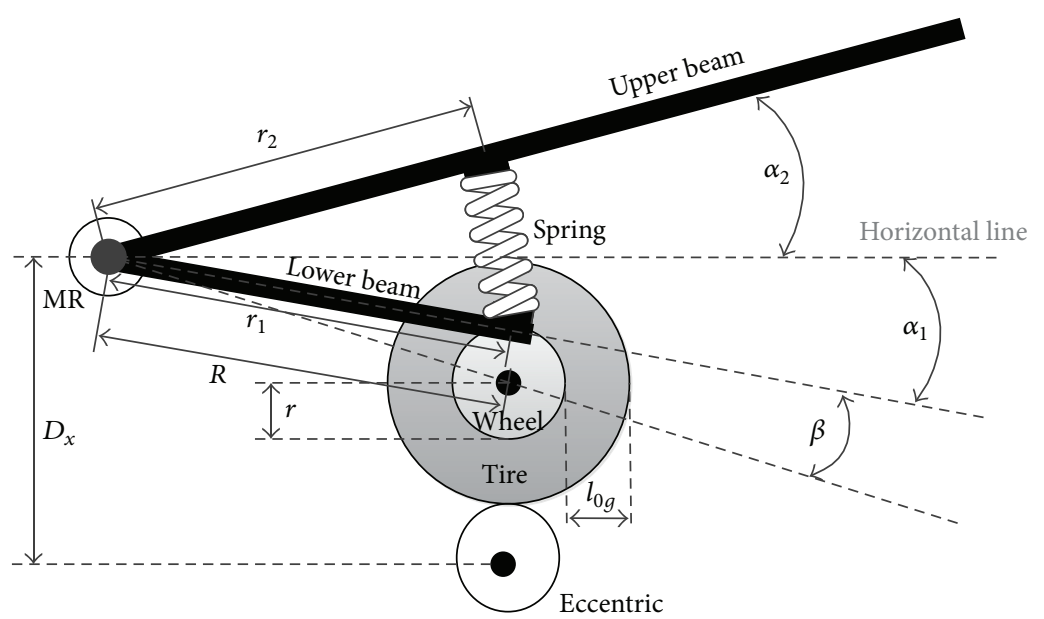

FIGURE 2: Geometrical diagram of SAS.

systems [20-24]. A simulation is done based on the dynamic model of the semiactive suspension (SAS) system and ADRC technology. The experimental task is also carried out to measure the performance of the controller in the real system.

\section{Semiactive Suspension System}

The semiactive suspension (SAS) system studied here for vibration suppression is developed by the Polish Company Inteco Limited [25]. This SAS system can be used to analyze the vertical dynamics of the car wheel. As shown in Figure 1, the SAS laboratory model simulated a quarter of a wheeled vehicle, and it consists of an upper beam which represents the car body, a wheel, rotational MR damper, and a spring. It is driven by a DC motor with gear coupled to an eccentric small wheel. The suspended car wheel rolls due to the eccentric wheel rotation and oscillates up and down due to the small wheel eccentricity. The MR damper incorporated in SAS acts as an interface between sensors (encoders), control algorithms, and mechanical structure of the suspension, using the external damper coil current to adjust the damping. The torque generated by the MR damper depends on the rotary velocity of the damper and the magnetic field strength.
Figure 2 depicts the geometrical view of the SAS system.

The dynamic model of the SAS is described by the following differential equations, in which the detailed definition of the angles $\alpha(\cdot)$ and the distances $r(\cdot)$ are referred to in the nomenclature.

The dynamic equation of the upper beam is

$$
J_{2} \frac{d^{2} \alpha_{2}}{d t^{2}}=T_{2}
$$

$T_{2}$ is the total torque added to the upper beam. It consists of the friction torque of the upper beam at the torsional joint at the MR damper point, the moment dual to gravity, the torque caused by the connecting spring, and the MR damper torque. The $T_{2}$ is given as the following equation:

$$
T_{2}=k_{2} \frac{d \alpha_{2}}{d t}-M_{2} \cos \alpha_{2}+r_{2} k_{s} l_{s}+\left(\frac{d \alpha_{1}}{d t}-\frac{d \alpha_{2}}{d t}\right) M_{\mathrm{MR}}(i)
$$

with

$$
l_{s}=l_{0 s}-\sqrt{\left(r_{2} \cos \alpha_{2}-r_{1} \cos \alpha_{1}\right)^{2}+\left(r_{2} \sin \alpha_{2}-r_{1} \sin \alpha_{1}\right)^{2}} .
$$


The dynamic equation of the lower beam is

$$
J_{1} \frac{d^{2} \alpha_{1}}{d t^{2}}=T_{1}
$$

$T_{1}$ is the total torque added to the lower beam. It consists of the friction torque of the lower beam at the torsional joint at the MR damper point, the moment dual to gravity, the torque caused by the connecting spring, the elastic torque caused by the moving tire, the friction torque caused by the moving tire, and the MR damper torque. The $T_{1}$ is given as the following equation:

$$
\begin{aligned}
T_{1}= & k_{1} \frac{d \alpha_{1}}{d t}-M_{1} \cos \left(\beta_{1}-\alpha_{1}\right)-r_{1} k_{s} l_{s} \\
& +k_{g} R \cos \left(\beta-\alpha_{1}\right) \\
& \times\left(l_{0 g}+R \sin \left(\beta-\alpha_{1}\right)+r-D_{x}+u_{\text {kin }}\right) \\
& +f_{g}\left(\frac{d\left(D_{x}-u_{\text {kin }}\right)}{d t}-\frac{d a_{1}}{d t} R \cos \left(\beta-\alpha_{1}\right)\right) \\
& +\left(\frac{d \alpha_{1}}{d t}-\frac{d \alpha_{2}}{d t}\right) M_{\mathrm{MR}}(i) .
\end{aligned}
$$

To emphasize the MR damper torque, we rewrite (1) and (4) depending on (2) and (5) and define

$$
T_{\mathrm{MR}}=\left(\frac{d \alpha_{1}}{d t}-\frac{d \alpha_{2}}{d t}\right) M_{\mathrm{MR}}(i) .
$$

We can give out the dynamic equation of the upper and lower beam as the following:

$$
\begin{aligned}
J_{2} & \frac{d^{2} \alpha_{2}}{d t^{2}}-k_{2} \frac{d \alpha_{2}}{d t}+M_{2} \cos \alpha_{2}-r_{2} k_{s} l_{s}=T_{\mathrm{MR}} \\
J_{1} \frac{d^{2} \alpha_{1}}{d t^{2}} & -k_{1} \frac{d \alpha_{1}}{d t}+M_{1} \cos \left(\beta_{1}-\alpha_{1}\right) \\
& +r_{1} k_{s} l_{s}-k_{g} R \cos \left(\beta-\alpha_{1}\right) \\
& \times\left(l_{0 g}+R \sin \left(\beta-\alpha_{1}\right)+r-D_{x}+u_{\mathrm{kin}}\right) \\
& -f_{g}\left(\frac{d\left(D_{x}-u_{\mathrm{kin}}\right)}{d t}-\frac{d a_{1}}{d t} R \cos \left(\beta-\alpha_{1}\right)\right)=T_{\mathrm{MR}}
\end{aligned}
$$

\section{Feedback Control with Extended State Observer (ESO)}

To suppress the vibration of the vehicle and make passengers feel comfortable mean that the aim of the control methodology is to decease the changing of $\alpha_{2}$ and try to make the system stable at certain degree. Therefore, in a feedback control method we mainly focus on the vibration of the body, so that we only use the dynamic of body movement.

Equation (7) can be expressed as

$$
J_{2} \ddot{\alpha}_{2}-k_{2} \dot{\alpha}_{2}+M_{2} \cos \alpha_{2}-r_{2} k_{s} l_{s}=T_{\mathrm{MR}}(i) \text {. }
$$

Define $x_{1}=\alpha_{2}$ and $x_{2}=\dot{x}_{1}=\dot{\alpha}_{2}$; then, we can rewrite (9) in the following:

$$
\begin{gathered}
\dot{x}_{1}=x_{2}, \\
\dot{x}_{2}=f\left(x_{1}, x_{2}, d(t)\right)+b u, \\
y=x_{1},
\end{gathered}
$$

where the ESO compensation coefficient $b=1 / J_{2}$; control torque produced by MR damper $u=T_{\mathrm{MR}}(i) ; d(t)=$ $r_{2} k_{s} l_{s} / J_{2}$ refers to the external disturbance. $f\left(x_{1}, x_{2}, d(t)\right)=$ $f\left(\alpha_{2}, \dot{\alpha}_{2}, d(t)\right)$, or simply donated as $f$, is a function of both the internal dynamics and the external disturbance and

$$
f=\frac{k_{2}}{J_{2}} \dot{\alpha}_{2}-\frac{M_{2}}{J_{2}} \cos \alpha_{2}+\frac{r_{2} k_{s} l_{s}}{J_{2}} .
$$

The output of the system is $y$.

The basic idea of the control methodology here is to obtain the estimated $f$ (or $\widehat{f}$ ) in the real-time by an extended state observer (ESO) and to actively compensate for it in the control law $[18,19]$.

Now we construct the ESO $[18,19]$, in the form of

$$
\begin{gathered}
e=z_{1}-y, \\
\mathrm{fe}=\mathrm{fal}(e, 0.5, \delta), \quad \mathrm{fe}_{1}=\mathrm{fal}(e, 0.25, \delta) \\
\dot{z}_{1}=z_{2}-\beta_{01} e, \\
\dot{z}_{2}=z_{3}+b u-\beta_{02} \mathrm{fe} \\
\dot{z}_{3}=-\beta_{03} \mathrm{fe}_{1}
\end{gathered}
$$

with

$$
\mathrm{fal}(e, \alpha, \delta)= \begin{cases}\frac{e}{\delta^{1-\alpha}}, & |e| \leq \delta \\ |e|^{\alpha} \operatorname{sign}(e) & |e|>\delta .\end{cases}
$$

There are many ways to select the observer gains $\beta_{01}, \beta_{02}$, and $\beta_{03}$ for a particular problem. In [19], the author proposes a group of gains when the sampling time $h$ of the system (simulation or real experiment) is chosen; the gains can be given as follows:

$$
\beta_{01}=\frac{1}{h}, \quad \beta_{02}=\frac{1}{1.6 h^{1.5}}, \quad \beta_{03}=\frac{1}{8.6 h^{2.2}} .
$$

The inputs to ESO are the system output $y$ and the control signal $u$, and the output of the ESO gives the important information $F(t)=f\left(x_{1}, x_{2}, d(t)\right)$. We can set the control law as $\left(u_{0}-F(t)\right) / b$ to reduce the plant in (10) to a cascade integral form of

$$
\begin{gathered}
\dot{x}_{1}=x_{2}, \\
\dot{x}_{2}=u_{0}, \\
y=x_{1} .
\end{gathered}
$$

Then, a PD controller is implemented to make $u_{0}$ a function of the tracking error and its derivative, and we can control the output of system $y$ to a near constant value to achieve the vibration suppression of the body. The whole process is shown in Figure 3. 


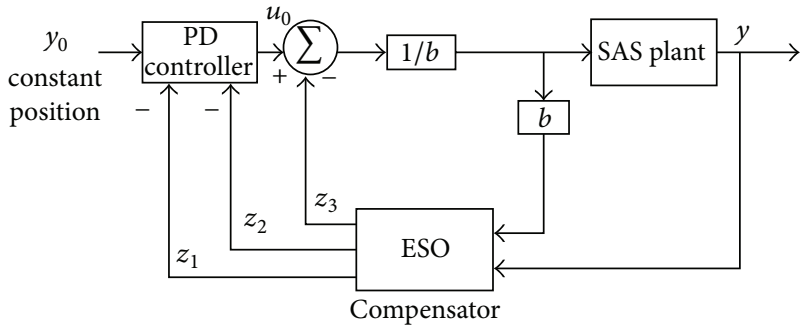

FIGURE 3: Vibration suppression feedback control of SAS based on ESO.

\section{MR Damper Model}

The MR damper is a type of semiactive damper where the viscosity of the MR fluid is controlled by varying the amount of the input current and hence changes the output torque. The output of the controller is torque and a MR damper model is needed to calculate the current both in simulation and experiment. To describe the hysteretic behavior of MR dampers, several models have been proposed in the literature, including the Bingham model, Dahl model, the Bouc-Wen model, Lurge model, and neural networks $[10,26]$. In this paper Dahl model is selected to model the MR damper [27].

The governing equations of the MR damper are

$$
\begin{gathered}
T_{\mathrm{MR}}=K_{x}(i) \dot{\theta}+K_{y}(i) z, \\
\dot{z}=\varepsilon(\dot{\theta}-|\dot{\theta}| z),
\end{gathered}
$$

where $\theta$ is the angle, $K_{x}$ is the damping coefficients which depend linearly on the current $i$, and $z$ is the hysteretic variable. Parameters $K_{y}$ and $\varepsilon$ control the shape of the hysteresis curve. $K_{x}$ and $K_{y}$ are described by the following equations:

$$
\begin{aligned}
& K_{x}=K_{a}+K_{b} i, \\
& K_{y}=K_{1}+K_{2} i .
\end{aligned}
$$

Damper torque given from the Dahl model is as follows:

$$
T_{\mathrm{MR}}=\left(K_{a}+K_{b} i\right) \dot{\theta}+\left(K_{1}+K_{2} i\right) z .
$$

Therefore, the control current that should be sent to the MR damper is

$$
i=\frac{T_{\mathrm{MR}}-K_{a} \dot{\theta}-K_{1} z}{K_{b} \dot{\theta}+K_{2} z} .
$$

We test and measure the MR damper parameters in the Dahl model from the SAS laboratory model and get them as the following:

$$
\begin{aligned}
& K_{1}=5, \quad K_{2}=1.5, \quad K_{a}=0.001, \\
& K_{b}=0.001, \quad \varepsilon=5 .
\end{aligned}
$$

\section{Numerical Results}

The system equations and feedback control method based on ESO are implemented in Matlab/Simulink to evaluate
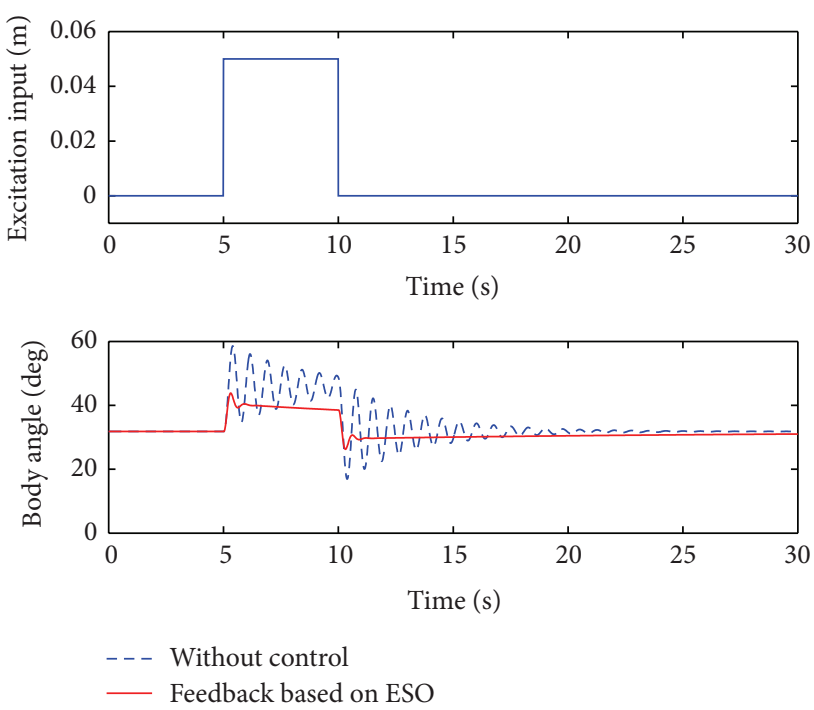

FIgURE 4: Step excitement input simulation results.
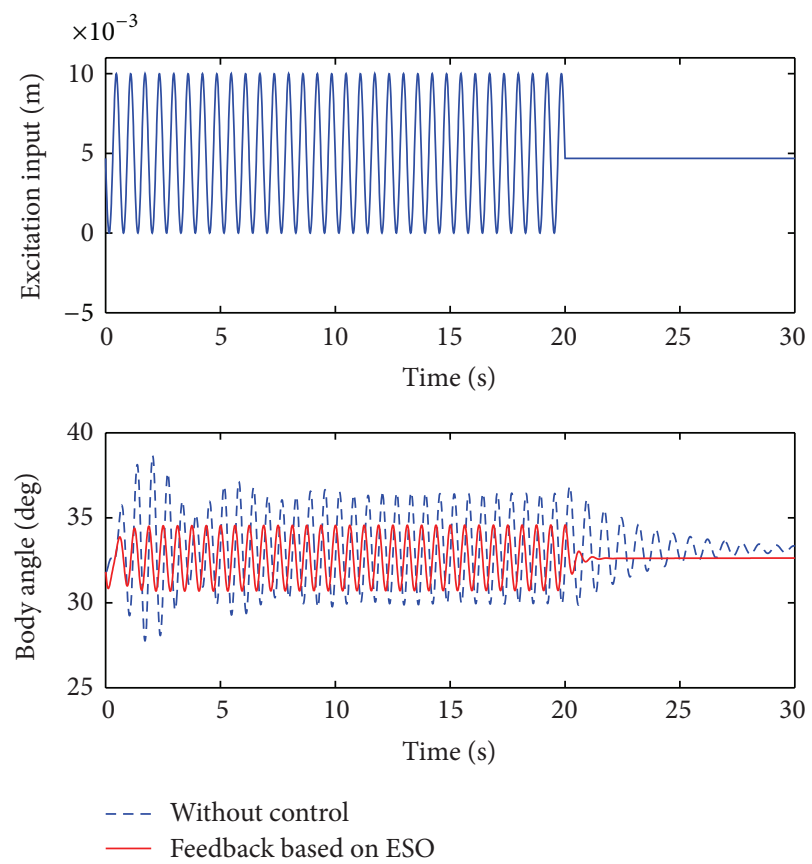

FIGURE 5: Continuous sinusoidal excitement input simulation results.

the system performance. In the simulation, we chose simulation environment as fix-step, with the ode3 solver and sampling time $h=0.01 \mathrm{~s}$. The ESO gains can be calculated by (14), and the results are $\beta_{01}=100, \beta_{02}=625$, and $\beta_{03}=2920.8$. The proportional gain and the differential gain of the PD controller are chosen as $P=1$ and $D=5$ for the purpose of making the loop stable. Different excitation inputs, step, continuous sinusoidal, and random sequence are taken to show the control results. Figures 4, 5, 6, and 7 illustrate that with the feedback control method based on ESO, the body is stabilized more quickly and the vibration 

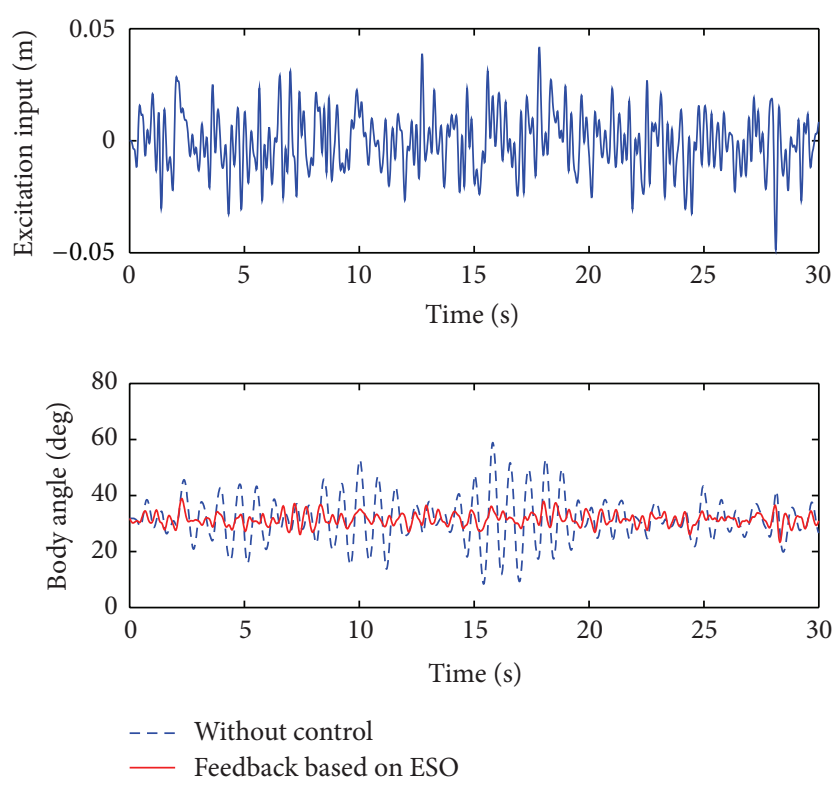

FIGURE 6: Random sequence excitement input simulation results.

is suppressed. The transmissibility of excitement input ( $\mathrm{mm}$ ) to body angle output (degree) is calculated based on random simulation data. The frequency range is between 0 and $5 \mathrm{~Hz}$, which is proper for the real excitation system. The simulation results in Figure 7 show that the vibration of the body is well suppressed at the frequency range by feedback control based on ESO.

\section{Experiment with Laboratory SAS System}

The SAS has been designed to operate with an external PCbased digital controller. The control computer communicates with the level sensors, valves, and pump by a dedicated I/O board and the power interface. The I/O board is controlled by the real-time software which operates in Matlab/Simulink/RTW rapid prototyping environment. RTW is short for real-time workshop.

From the MR damper model we can see that a velocity of angle is needed to calculate the current; however, the hardware I/O board just returns angle information. In the real signal processing, it is difficult to get the differential information of a certain signal. So here we introduce the tracking differentiator (TD for short) method to calculate velocity information from the angle. The tracking differentiator can be found in $[18,28]$. The form of TD here is nonlinear because of its good property of tracking differential information of original signals which are covered by sensor white noise $[28,29]$. The discrete signals $v_{1}$ and $v_{2}$ of TD are the traces of the reference input $v$ following an optimal path:

$$
\begin{gathered}
v_{1}(k+1)=v_{1}(k)+h v_{2}(k) \\
v_{2}(k+1)=v_{2}(k)+h \text { fhan }\left(v_{1}(k)-v(k), v_{2}(k), r_{0}, h_{0}\right),
\end{gathered}
$$

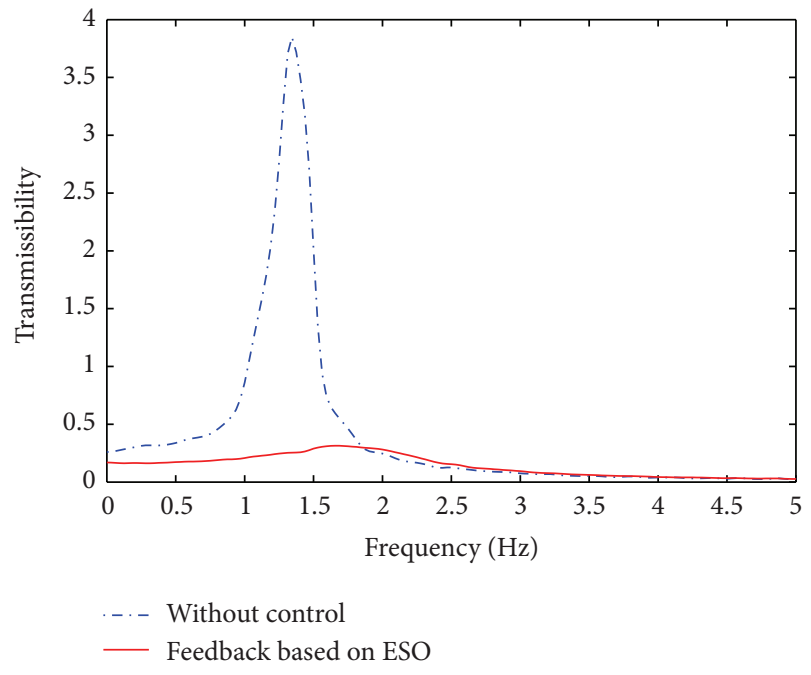

Figure 7: Transmissibility of excitement input (mm) to body angle output (degree) of simulation.

where $h$ is the sampling step, $r$ is the tracking velocity factor for signal tracking, and $h_{0}$ is the filtering factor to reject stochastic noise. The update function fhan $\left(p_{1}, p_{2}, r, H\right)$ is of the form

$$
\text { fhan }\left(p_{1}, p_{2}, r, H\right)= \begin{cases}-r_{0} \operatorname{sign}(a), & |a|>d \\ -r_{0} \frac{a}{d}, & |a| \leq d\end{cases}
$$

with

$$
\begin{gathered}
\operatorname{sign}(a)= \begin{cases}-1, & a<0 \\
0, & a=0 \\
1, & a>0,\end{cases} \\
a= \begin{cases}p_{1}+\frac{c-d}{2} \operatorname{sign}(\gamma), & |\gamma|>d^{2} \\
p_{2}+\frac{\gamma}{d}, & |\gamma| \leq d^{2},\end{cases} \\
d=r_{0} H, \quad \gamma=r_{0} p_{1}+d p_{2}, \quad c=\sqrt{d^{2}+8|\gamma| .}
\end{gathered}
$$

The smoothed velocity $x_{2}$, which is the velocity of MR damper angle $\alpha_{2}$, is derived from

$$
\begin{aligned}
& x_{1}(k+1)=x_{1}(k)+h x_{2}(k) \\
x_{2}(k+1)= & x_{2}(k) \\
& +h \text { fhan }\left(x_{1}(k)-\alpha_{2}(k), x_{2}(k), r_{0}, h_{0}\right) .
\end{aligned}
$$

In the experiment the parameters are chosen as the following: $r_{0}=5, h=0.01$, and $h_{0}=0.1$. Figure 8 shows the results of MR damper angular velocity when input excitement is continuous sinusoidal.

Feedback control method based on the ESO has been taken experiment on the SAS laboratory system, and the MATLAB/Simulink program environment was used to realize the control method. With the tracking differentiator, 


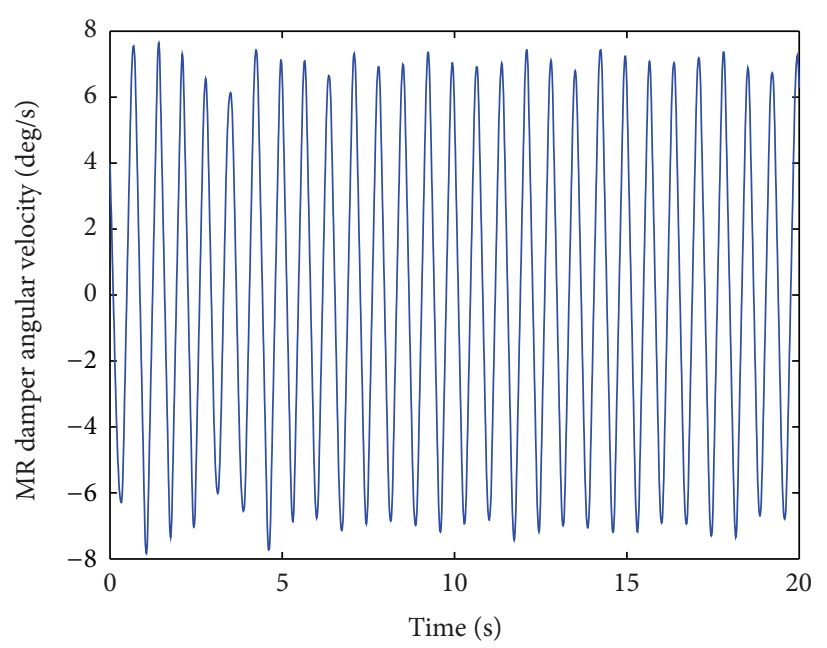

FIGURE 8: Tracking results of MR damper angular velocity with a continuous sinusoidal excitement.

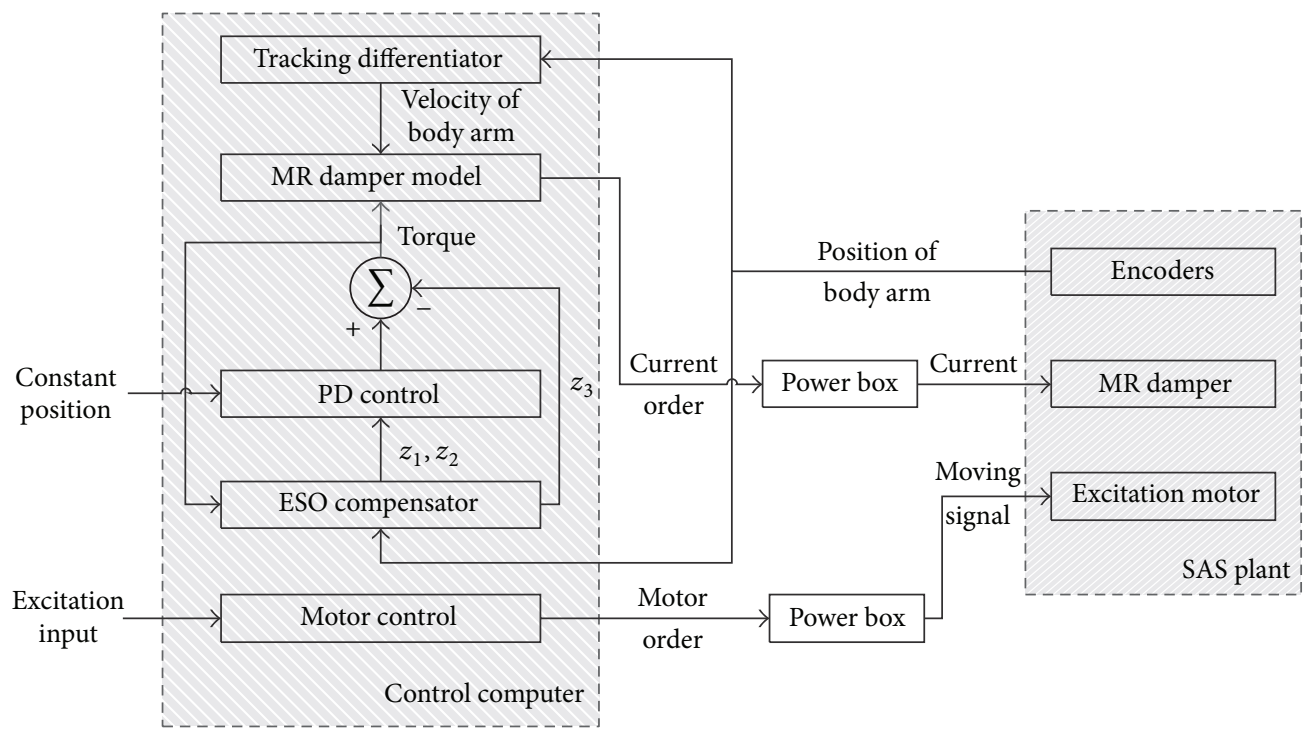

FIGURE 9: The control structure diagram of the experiment.

the MR damper model, PD control, ESO compensator, excitation input control, and the SAS plant, the control structure diagram of the experiment is shown in Figure 9. And the control program diagram for experiment with SAS hardware interface in the Matlab/Simulink is shown in Figure 10.

The similar excitation inputs as in the numerical simulation are taken in the experiment in order to compare with the former simulation results. The vibrations are introduced by the eccentric wheel, so the excitements are always from 0 to $6 \mathrm{~mm}$. The vibration response of the body angle is obtained with and without feedback controller based on ESO. Figures $11,12,13$, and 14 illustrate the experiment results.

According to the experimental results, as in the simulation, in the cases of step, continuous sinusoidal, and random sequence excitements, we can see that with the feedback control based on ESO the vibration of the upper beam (the body) is suppressed and the body is stabilized much faster than without control. The transmissibility of excitement input ( $\mathrm{mm}$ ) to body angle output (degree) is calculated based on random experiment data. The frequency range is between 0 and $5 \mathrm{~Hz}$, which is proper for the real excitation system. The experiment results in Figure 14 show that the vibration of the body is well suppressed at the frequency range by feedback control based on ESO. There was an input current limitation of the MR damper in the SAS system, so the control results in experiments did not achieve the fine ability as in simulation.

The vibration response of a freely released beam after suppression is depicted in Figure 15. With the controller based on ESO, the body is stabilized much faster.

\section{Conclusion}

The SAS system represents a quarter wheeled vehicle model, and it uses a MR damper to semiactively reduce the vibration. 


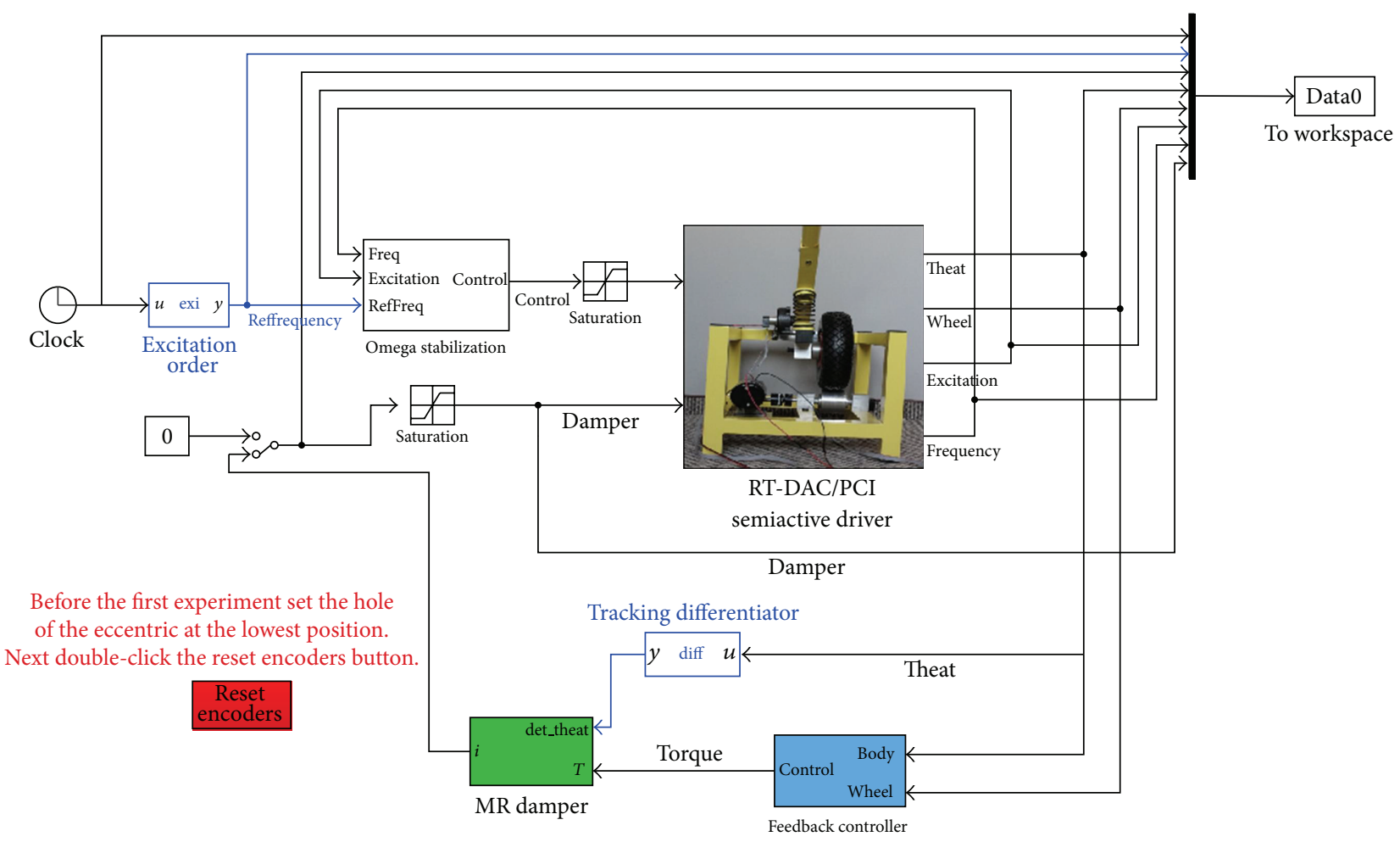

FIGURE 10: Real-time experimental Simulink model of the SAS with feedback control base on ESO.
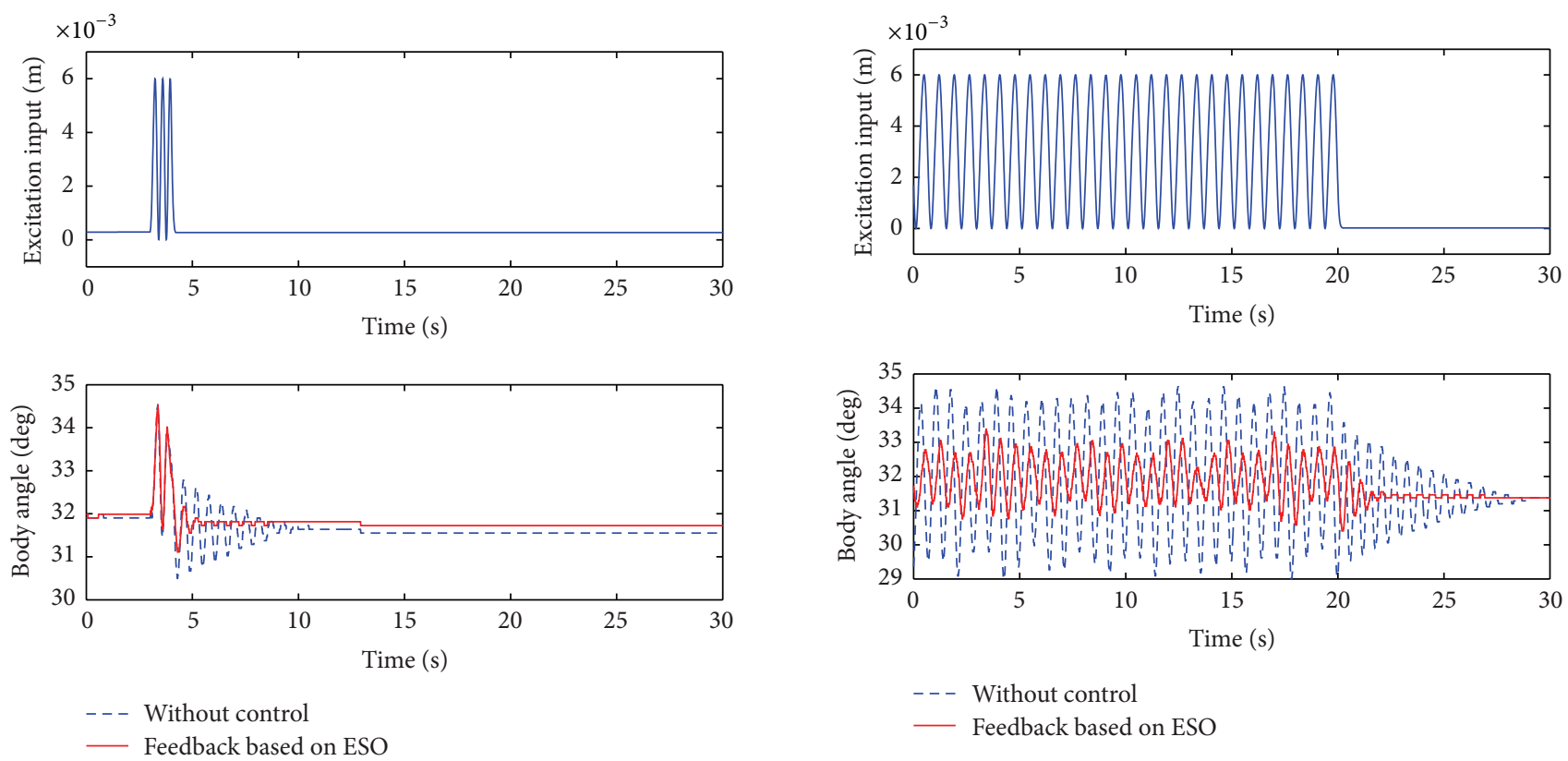

FIGURE 11: Step excitement input experimental results

The output torque of the MR damper can be changed by the input of the current, and we use feedback controller to implant vibration suppression control to the SAS system based on the function of MR damper. The controller is based on ESO, the main part of ADRC technology.

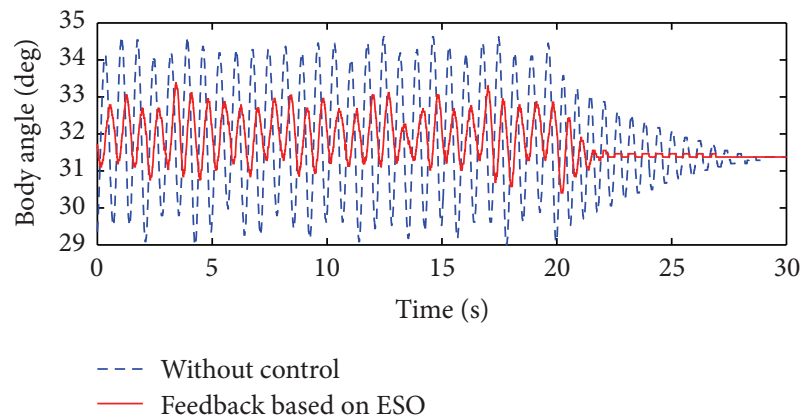

FIGURE 12: Continuous sinusoidal excitement input experimental results.

The proposed controller is tested in numerical simulation as well as real-time experiments with various vibration input signals. The simulation and experimental results both show the good quality of the controller. The controller depends on less information of system model and can observe inner and 

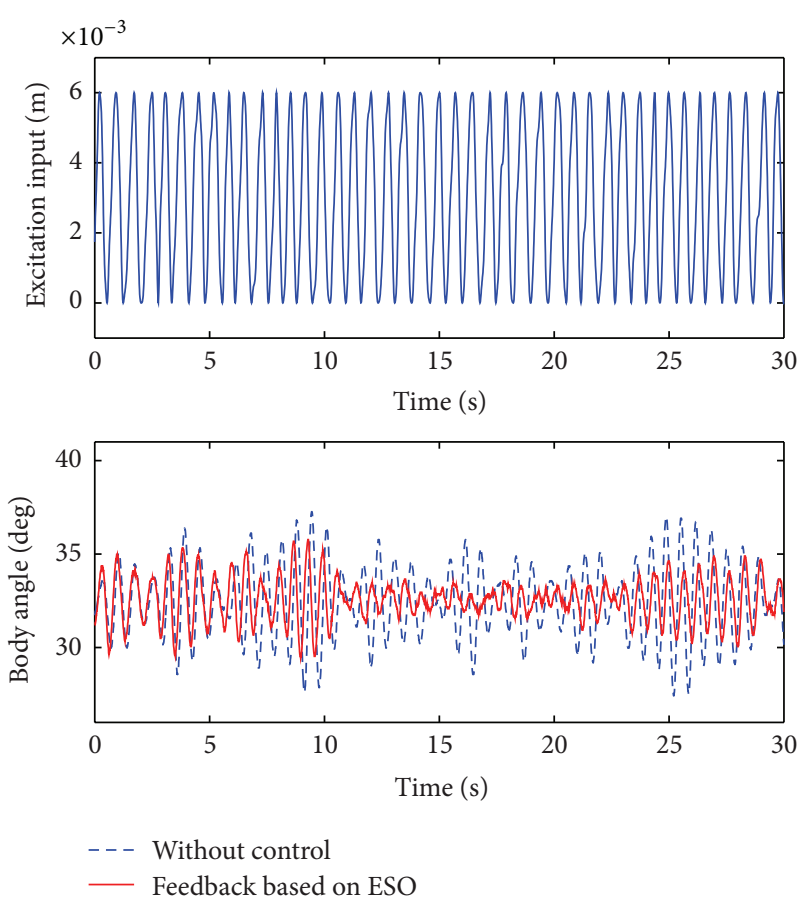

FIGURE 13: Random excitement input experimental results.

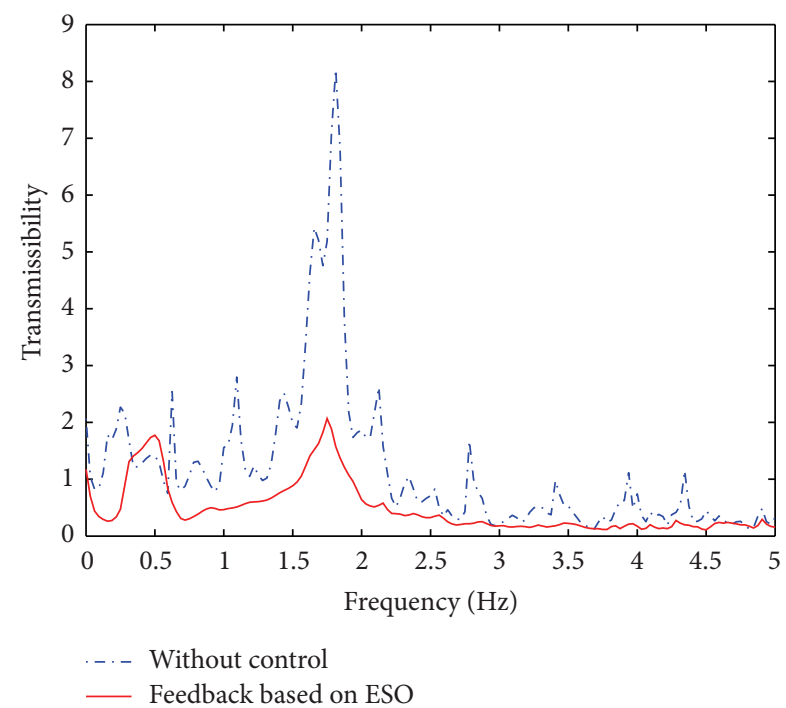

FIgURE 14: Transmissibility of excitement input ( $\mathrm{mm})$ to body angle output (degree) of experiment.

outer disturbances in real-time to counterweigh them, so it has potential to be applied to a whole vehicle model with a group of four independent controllers base on ESOs in the future research.

\section{Nomenclature}

$b$ : Compensation coefficient of ESO

$D$ : Differential gain of PD controller

$D_{x}$ : Distance between the beam pivot and the pivot of the eccentric

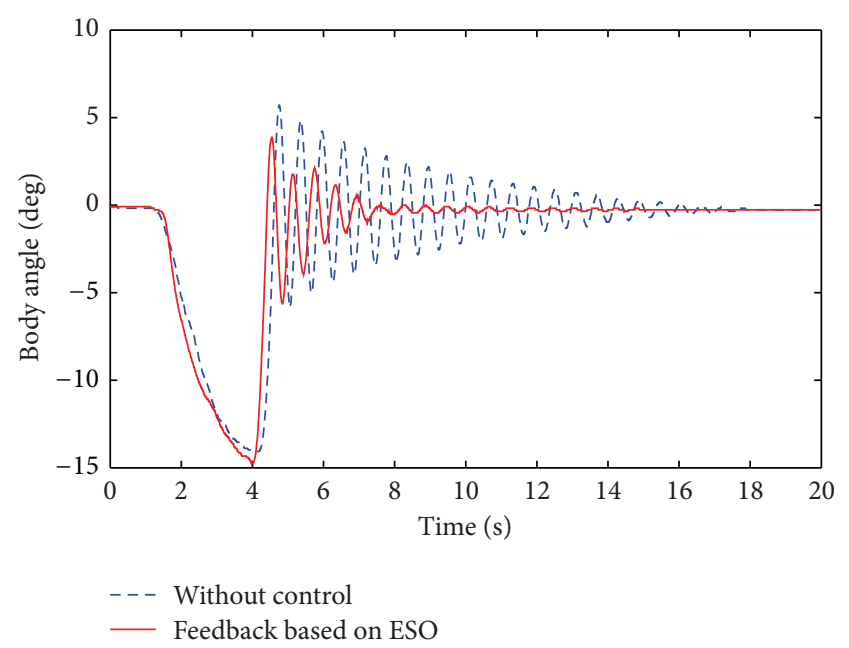

FIGURE 15: Experimental results of the body angle for releasing the beam after suppression.

e: $\quad$ Error of state variables $z_{1}$ and the system

$f$ : $\quad$ External disturbance

$f_{g}: \quad$ Absorption coefficient of the tire

$h$ : $\quad$ Sampling time

$h_{0}$ : $\quad$ Filtering factor to reject stochastic noise of TD

$i$ : $\quad$ Input current of the MR damper

$J_{1}, J_{2}$ : Moment of inertia of the lower and upper beam with respect to its rotation axis

$k_{1}, k_{2}$ : Viscous friction coefficient of the lower and upper beam

$K_{1}, K_{2}$ : Parameters of defining $K_{y}$ in the MR damper Dahl model

$K_{a}, K_{b}$ : Parameters of defining $K_{x}$ in the MR damper Dahl model

$k_{g}: \quad$ Elasticity coefficient of the tire

$k_{s}$ : $\quad$ Elasticity coefficient of the spring

$K_{x}$ : Damping coefficients depended linearly on the current

$k_{y}$ : $\quad$ Parameter control the shape of the hystere-

sis curve of the MR damper

$l_{0 s}: \quad$ Length of the no-load spring

$l_{s}$ : $\quad$ Stretching length of the spring

$M_{1}, M_{2}$ : Gravitational moment of the lower and upper beam

$M_{\mathrm{MR}}(i)$ : Static profile of the MR damper

$P: \quad$ Proportional gain of PD controller

$r: \quad$ Radius of the wheel rim

$r_{0}$ : Tracking velocity factor for signal tracking of TD

$r_{1}, r_{2}$ : Distance between the spring mount and the beam (the lower and the upper)

$R: \quad$ Distance between the MR damper and the center of the tire

$T_{1}, T_{2}$ : Total torque added to the lower and upper beam

$T_{\mathrm{MR}}: \quad$ MR damper torque 


\begin{tabular}{|c|c|}
\hline$u$ : & Control torque produced by MR damper \\
\hline$u_{0}:$ & Output of the PD controller \\
\hline$u_{\text {kin }}:$ & Kinetic sinusoidal excitation \\
\hline$x_{1}:$ & Equal to the angel vibrate $\alpha_{2}$ \\
\hline$x_{2}:$ & Time derivative of $x_{1}$ \\
\hline$y:$ & System output \\
\hline$y_{0}:$ & Desired constant position \\
\hline$z:$ & $\begin{array}{l}\text { Hysteretic variable of the MR damper Dahl } \\
\text { model }\end{array}$ \\
\hline$z_{1}, z_{2}, z_{3}$ & Observed system state variables of the ESO \\
\hline$\alpha:$ & Vibration of fal function \\
\hline$\alpha_{1}:$ & $\begin{array}{l}\text { Angle between the lower beam and the } \\
\text { horizontal line }\end{array}$ \\
\hline$\alpha_{2}:$ & $\begin{array}{l}\text { Angle between the upper beam and the } \\
\text { horizontal line }\end{array}$ \\
\hline$\beta:$ & $\begin{array}{l}\text { Angle between lower beam and the hori- } \\
\text { zontal line }\end{array}$ \\
\hline$\beta_{01}, \beta_{02}, \beta_{03}:$ & Regulation gains of ESO \\
\hline$\delta:$ & Vibration of fal function \\
\hline$\varepsilon:$ & $\begin{array}{l}\text { Parameter that controls the shape of the } \\
\text { hysteresis curve of the MR damper }\end{array}$ \\
\hline$\theta:$ & Relative angle of MR damper. \\
\hline
\end{tabular}

\section{Conflict of Interests}

The authors declare that there is no conflict of interests regarding the publication of this paper.

\section{Acknowledgment}

The research leading to these results has received funding from the Polish-Norwegian Research Programme operated by the National Centre for Research and 24 Development under the Norwegian Financial Mechanism 2009-2014 in the frame of Project Contract no. Pol-Nor/200957/47/2013.

\section{References}

[1] I. Eski and Ş. Yıldırım, "Vibration control of vehicle active suspension system using a new robust neural network control system," Simulation Modelling Practice and Theory, vol. 17, no. 5, pp. 778-793, 2009.

[2] W. Sun, H. Gao Sr., and O. Kaynak, "Finite frequency $H_{\infty}$ control for vehicle active suspension systems," IEEE Transactions on Control Systems Technology, vol. 19, no. 2, pp. 416-422, 2011.

[3] H. Li, X. Jing, and H. R. Karimi, "Output-feedback based $H_{\infty}$ control for active suspension systems with control delay," IEEE Transactions on Industrial Electronics, vol. 61, no. 1, pp. 436-446, 2014.

[4] W. Sun, Y. Zhao, J. Li, L. Zhang, and H. Gao, "Active suspension control with frequency band constraints and actuator input delay," IEEE Transactions on Industrial Electronics, vol. 59, no. 1, pp. 530-537, 2012.

[5] J. Rubio-Massegu, F. Palacios-Qui?onero, J. M. Rossell, and H. R. Karimi, "Static output-feedback control for vehicle suspensions: a single-step linear matrix inequality approach," Mathematical Problems in Engineering, vol. 2013, Article ID 907056, 12 pages, 2013.

[6] Y. Zhang, G. Liu, P. Wang, and H. R. Karimi, "Finite frequency vibration control for polytopic active suspensions via dynamic output feedback," Mathematical Problems in Engineering, vol. 2013, Article ID 598489, 12 pages, 2013.

[7] Q. Yang, J. Huang, G. Wang, and H. R. Karimi, "An adaptive metamodel-based optimization approach for vehicle suspension system design," Mathematical Problems in Engineering, vol. 2014, Article ID 965157, 9 pages, 2014.

[8] K. Yi and B. S. Song, "A new adaptive sky-hook control of vehicle semi-active suspensions," Proceedings of the Institution of Mechanical Engineers, Part D: Journal of Automobile Engineering, vol. 213, no. 3, pp. 293-303, 1999.

[9] M. Zapateiro, F. Pozo, H. R. Karimi, and N. Luo, "Semiactive control methodologies for suspension control with magnetorheological dampers," IEEE/ASME Transactions on Mechatronics, vol. 17, no. 2, pp. 370-380, 2012.

[10] F. Imaduddin, S. A. Mazlan, and H. Zamzuri, "A designand modelling review of rotary magnetor- heological damper," Materials \& Design, vol. 17, no. 51, pp. 575-591, 2013.

[11] N. Aguirre, F. Ikhouane, and J. Rodellar, "Proportional-plusintegral semiactive control using magnetorheological dampers," Journal of Sound and Vibration, vol. 330, no. 10, pp. 2185-2200, 2011.

[12] M. Zapateiro, N. Luo, H. R. Karimi, and J. Vehí, "Vibration control of a class of semiactive suspension system using neural network and backstepping techniques," Mechanical Systems and Signal Processing, vol. 23, no. 6, pp. 1946-1953, 2009.

[13] M. Zapateiro, H. R. Karimi, N. Luo, and B. F. Spencer Jr., "Realtime hybrid testing of semiactive control strategies for vibration reduction in a structure with MR damper," Structural Control and Health Monitoring, vol. 17, no. 4, pp. 427-451, 2010.

[14] M. Zapateiro, H. R. Karimi, N. Luo, B. M. Phillips, and B. F. Spencer Jr., "Semiactive backstepping control for vibration reduction in a structure with magnetorheological damper subject to seismic motions," Journal of Intelligent Material Systems and Structures, vol. 20, no. 17, pp. 2037-2053, 2009.

[15] M. Bitaraf, O. E. Ozbulut, S. Hurlebaus, and L. Barroso, "Application of semi-active control strategies for seismic protection of buildings with MR dampers," Engineering Structures, vol. 32, no. 10, pp. 3040-3047, 2010.

[16] U. Aldemir, "Causal semiactive control of seismic response," Journal of Sound and Vibration, vol. 322, no. 4-5, pp. 665-673, 2009.

[17] M. Zapateiro, H. R. Karimi, and N. Luo, "Semiactive vibration control of nonlinear structures through adaptive backstepping techniques with $H_{\infty}$ performance," International Journal of Systems Science, vol. 42, no. 5, pp. 853-861, 2011.

[18] J. Han, "From PID to active disturbance rejection control," IEEE Transactions on Industrial Electronics, vol. 56, no. 3, pp. 900906, 2009.

[19] J. Han, Active Disturbance Rejection Control Technique-the Technique for Estimating and Compensating the Uncertainties, National Defense Industry Press, Beijing, China, 2009, (Chinese).

[20] Z. Ping and Z. Gao, "An FPGA-based digital control and communication module for space power management and distribution systems," in Proceedings of the American Control Conference (ACC '05), pp. 4941-4946, June 2005.

[21] Q. Zheng, L. Dong, D. H. Lee, and Z. Gao, "Active disturbance rejection control for MEMS gyroscopes," IEEE Transactions on Control Systems Technology, vol. 17, no. 6, pp. 1432-1438, 2009.

[22] D. Wu and K. Chen, "Design and analysis of precision active disturbance rejection control for noncircular turning process," 
IEEE Transactions on Industrial Electronics, vol. 56, no. 7, pp. 2746-2753, 2009.

[23] M. Pizzocaro, D. Calonico, C. Calosso et al., "Active disturbance rejection control of temperature for ultrastable optical cavities," IEEE Transactions on Ultrasonics, Ferroelectrics, and Frequency Control, vol. 60, no. 2, pp. 273-280, 2013.

[24] K. Erenturk, "Fractional-order $\mathrm{PI} \lambda \mathrm{D} \mu$ and active disturbance rejection control of nonlinear two-mass drive system," IEEE Transactions on Industrial Electronics, vol. 60, no. 9, pp. 38063813, 2013.

[25] Semiactive Suspension System, User's Manual, INTECO Limited, 2007.

[26] J. An and D.-S. Kwon, "Modeling of a magnetorheological actuator including magnetic hysteresis," Journal of Intelligent Material Systems and Structures, vol. 14, no. 9, pp. 541-550, 2003.

[27] N. Aguirre Carvajal, F. Ikhouane, J. Rodellar Benedé, D. Wagg, and S. Neild, "Viscous + Dahl model for MR dampers characterization: A Real Time Hybrid Test (RTHT) validation," in Proceedings of the European Conference on Earthquake Engineering, Ohrid, Republic of Macedonia, 2010.

[28] J. Lin, K. W. E. Cheng, Z. Zhang et al., "Active suspension system based on linear switched reluctance actuator and control schemes," IEEE Transactions on Vehicular Technology, vol. 62, no. 2, pp. 562-572, 2013.

[29] Y. Tang, Y. Wu, M. Wu, X. Hu, and L. Shen, "Nonlinear tracking-differentiator for velocity determination using carrier phase measurements," IEEE Journal on Selected Topics in Signal Processing, vol. 3, no. 4, pp. 716-725, 2009. 


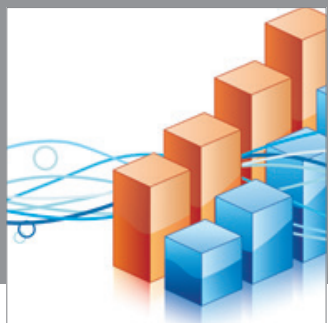

Advances in

Operations Research

mansans

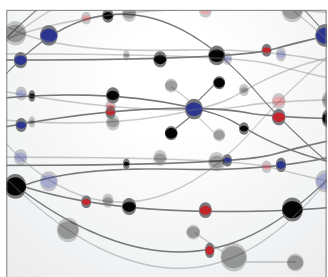

The Scientific World Journal
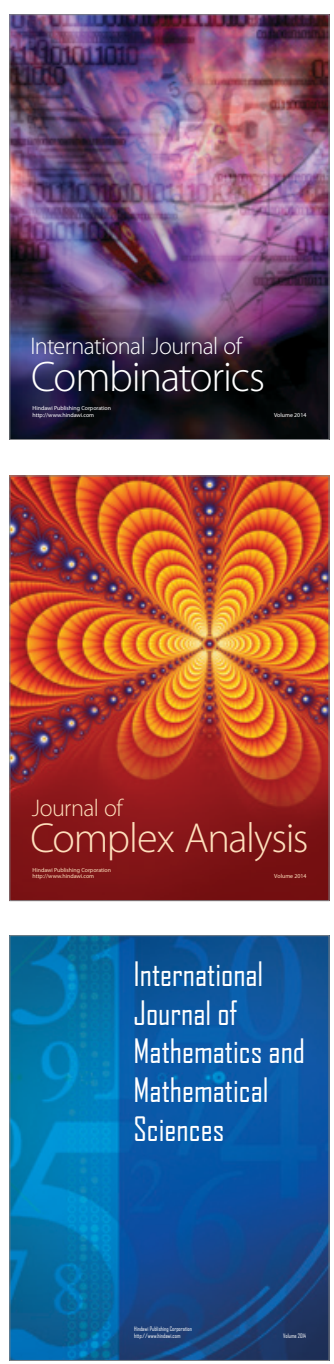
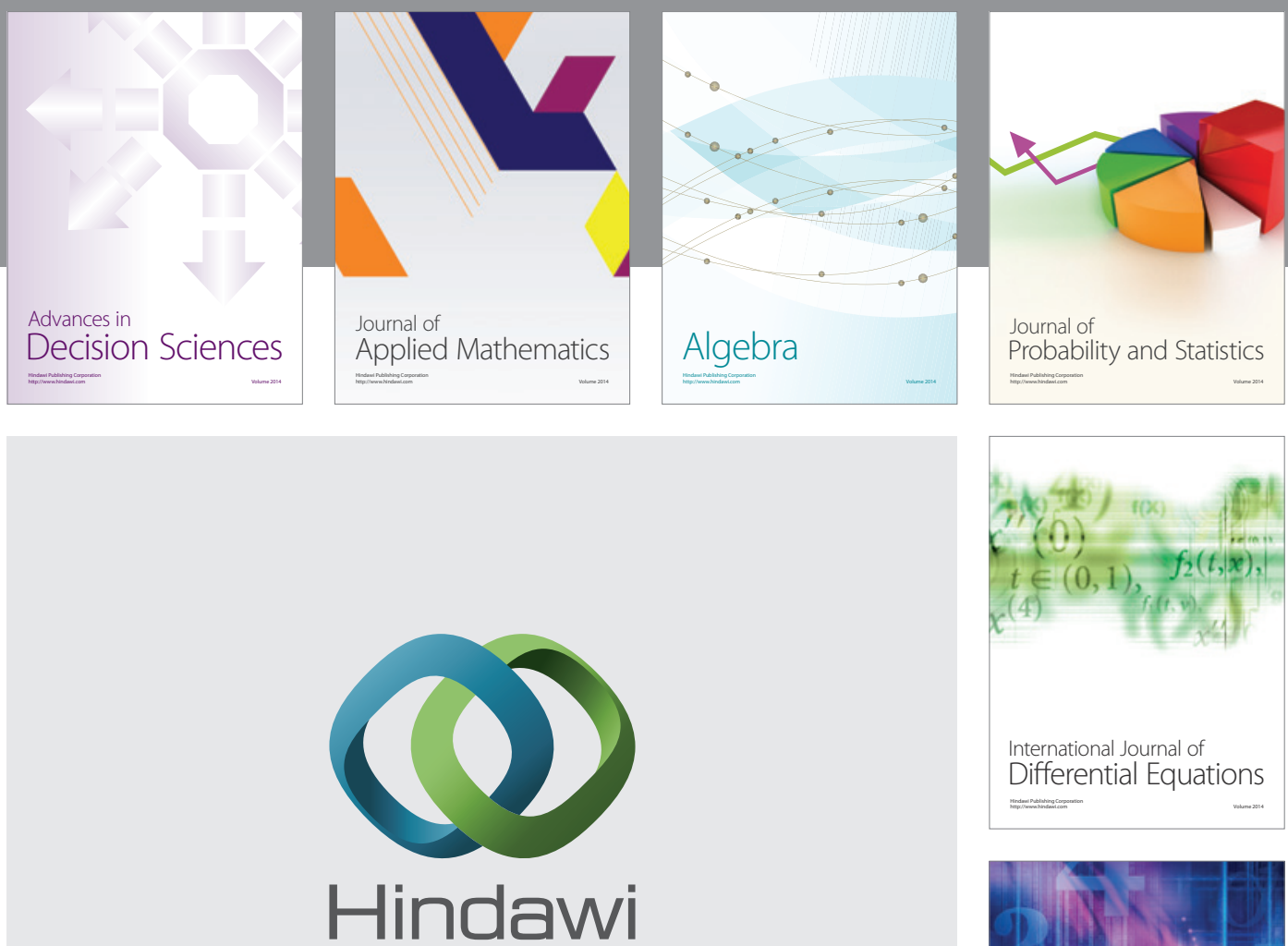

Submit your manuscripts at http://www.hindawi.com
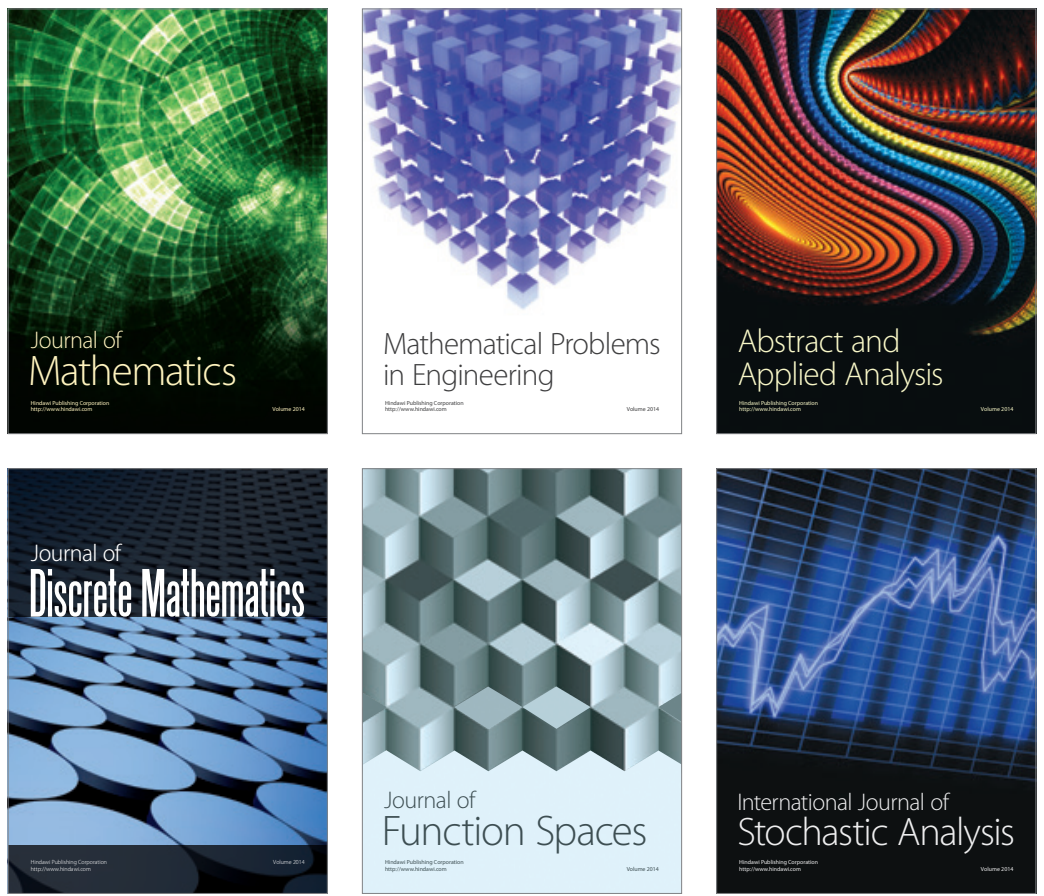

Journal of

Function Spaces

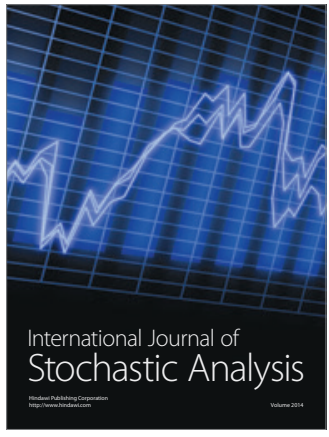

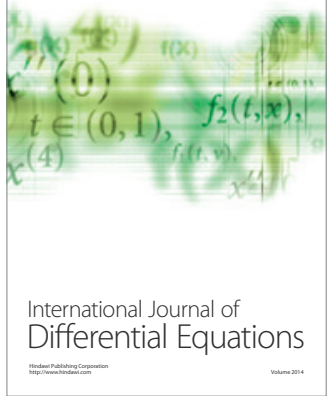
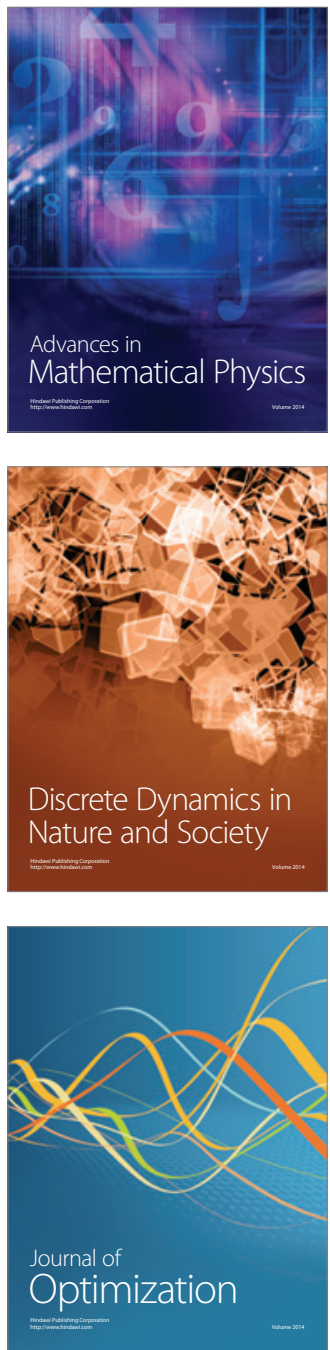